\title{
Antiviral effects of ergosterol peroxide in a pig model of porcine deltacoronavirus (PDCoV) infection involves modulation of apoptosis and tight junction in the small intestine
}

\author{
Cong Duan ${ }^{1}$, Junchi Wang ${ }^{2}$, Yi Liu' ${ }^{1}$, Jialu Zhang ${ }^{1}$, Jianyong $\mathrm{Si}^{2^{*}}$, Zhihui Hao ${ }^{1 *}$ and Jiufeng Wang ${ }^{1 *}$ (D)
}

\begin{abstract}
Porcine deltacoronavirus (PDCoV) is a newly discovered swine enteropathogenic coronavirus with worldwide distribution. However, efficient strategies to prevent or treat the infection remain elusive. Our in vitro study revealed that ergosterol peroxide (EP) from the mushroom Cryptoporus volvatus has efficient anti-PDCoV properties. The aim of this study is to evaluate the potential of EP as a treatment for PDCoV in vivo and elucidate the possible mechanisms. Seven-day-old piglets were infected with PDCoV by oral administration in the presence or absence of EP. Piglets infected with PDCoV were most affected, whereas administration of EP reduced diarrhea incidence, alleviated intestinal lesion, and decreased viral load in feces and tissues. EP reduced PDCoV-induced apoptosis and enhanced tight junction protein expressions in the small intestine, maintaining the integrity of the intestinal barrier. EP showed immunomodulatory effect by suppressing PDCoV-induced pro-inflammatory cytokines and the activation of IKBa and NF-KB p65, and upregulating IFN-I expression. Knockdown of p38 inhibited PDCoV replication and alleviated PDCoVinduced apoptosis, implying that EP inhibited PDCoV replication and alleviated PDCoV-induced apoptosis via p38/ MAPK signaling pathway. Collectively, ergosterol peroxide can protect piglets from PDCoV, revealing the potential of EP for development as a promising strategy for treating and controlling the infection of PDCoV.
\end{abstract}

Keywords: Ergosterol peroxide, Porcine deltacoronavirus, Immunomodulatory, Antiviral, Intestinal barrier

\section{Introduction}

Porcine deltacoronavirus (PDCoV) is a swine enteropathogenic coronavirus $(\mathrm{CoV})$ that can cause severe dehydration, vomiting and watery diarrhea in piglets, and belongs to the genus Deltacoronavirus of the family Coronaviridae [1]. Since its first outbreak in the United

\footnotetext{
*Correspondence: jysi@implad.ac.cn; haozhihui@cau.edu.cn; jiufeng_ wang@hotmail.com

${ }^{1}$ College of Veterinary Medicine, China Agricultural University, Beijing, China

${ }^{2}$ Institute of Medicinal Plant Development, Chinese Academy of Medical Sciences and Peking Union Medical College, Beijing, China
}

States in 2014 [2], PDCoV has rapidly spread to many countries, including South Korea, Japan, Thailand and China [3-6]. PDCoV can infect a variety of animals, including calves and poultry [7, 8], highlighting its ability to cross interspecies barriers. However, effective therapeutics or vaccines to control PDCoV infection are still limited, emphasizing the urgent need for the development of drugs against PDCoV.

Our recent study has shown that ergosterol peroxide (EP) from the mushroom Cryptoporus volvatus possesses efficient anti-PDCoV properties [9]. It can reduce LLC-PK1 cells apoptosis caused by PDCoV infection.

(c) The Author(s) 2021. This article is licensed under a Creative Commons Attribution 4.0 International License, which permits use, sharing, adaptation, distribution and reproduction in any medium or format, as long as you give appropriate credit to the original author(s) and the source, provide a link to the Creative Commons licence, and indicate if changes were made. The images or other third party material in this article are included in the article's Creative Commons licence, unless indicated otherwise in a credit line to the material. If material is not included in the article's Creative Commons licence and your intended use is not permitted by statutory regulation or exceeds the permitted use, you will need to obtain permission directly from the copyright holder. To view a copy of this licence, visit http://creativeco mmons.org/licenses/by/4.0/. The Creative Commons Public Domain Dedication waiver (http://creativecommons.org/publicdomain/ zero/1.0/) applies to the data made available in this article, unless otherwise stated in a credit line to the data. 
Apoptosis is a double-edged sword mechanism, which is used by the host to eliminate viruses and is manipulated by the virus to cause cytopathic effects in vitro and/ or tissue damage in vivo [10]. The massive apoptosis of enterocytes affects the integrity of the intestinal barrier [11]. The intestinal barrier is vital in maintaining selective gut permeability to allow for nutrient absorption and preventing pathogens from entering the blood circulation. The alteration of the intestinal barrier function is believed to be involved in the pathogenesis of gut diseases. Tight junction (TJ) proteins (including claudin-1, occludin and ZO-1) comprise another mechanism that maintains the integrity of the intestinal barrier [11]. As far as we know, there is no relevant reports on the effect of PDCoV on TJ proteins in piglets. Thus, the effects of EP on modulating PDCoV-induced apoptosis and the impact of PDCoV on TJ proteins need to be elucidated in vivo.

$\mathrm{T}$ lymphocytes are central players in orchestrating immune responses. $\mathrm{CD} 4^{+} \mathrm{T}$ cells can promote effective immunity protection through direct effector functions and by helping other leukocytes to maximize the protective activities [12]. The activated $\mathrm{CD}^{+}{ }^{+} \mathrm{T}$ cells are tailored to different types of pathogens through differentiation into functionally distinct subsets of effector $\mathrm{T}$ cells (Th1, Th2, and Th17) defined by expression of key transcription factors [13]. When responding to viral infection, the $\mathrm{CD} 4^{+} \mathrm{T}$ cells mainly have a Th1-type phenotype expressing T-bet and produce large amounts of IFNY [12]. However, little is known about the changes of $\mathrm{CD}^{+}{ }^{+} \mathrm{T}^{- \text {bet }^{+/-}} \mathrm{IFNY}^{+/-} \mathrm{T}$ cells after PDCoV infection.

The NF- $\mathrm{kB}$ signaling pathway is an evolutionarily conserved pathway that regulates a variety of physiological and pathological processes, functioning as a crucial coordinator of inflammatory and immune response [14]. $\mathrm{NF}-\mathrm{kB}$ is highly activated in diverse CoVs and the NF- $\mathrm{kB}-$ induced inflammatory response plays an important role in the development of pathogenesis and disease in CoVs infections $[15,16]$. PDCoV infection induces NF- $\mathrm{kB}$ activation and cytokine expression, which can be alleviated with the addition of EP in vitro [9]. Here, we detected whether there were similar phenomena in vivo.

Because viruses entirely depend on host cells to complete their life cycle, they coevolve with the host to adjust preexisting intracellular signal transduction networks to benefit their own multiplication $[17,18]$. The p38 mitogen-activated protein kinase (MAPK) pathway is a wellknown signal transducer that responds to extracellular stimulation by cytokines, stress, and viral infection, and in turn regulates cell differentiation, survival, and apoptosis [19]. Our previous study showed that p38 inhibitor inhibited PDCoV replication and EP alleviated p38 activation induced by $\mathrm{PDCoV}$ infection in vitro [9].
Herein, we characterized the inhibitory effects of EP against $\mathrm{PDCoV}$ in vivo. We hypothesized that apoptosis, $\mathrm{TJ}$ proteins, NF- $\mathrm{kB}$ and $\mathrm{p} 38$ /MAPK signaling pathways in the small intestine would be involved in the mechanisms by which EP alleviated PDCoV-associated pathological manifestation in piglets. A PDCoV infection model using LLC-PK1 cells was also established to address the role of p38/MAPK signaling pathway in the anti-PDCoV effects of EP.

\section{Materials and methods \\ Preparation of EP}

Ergosterol peroxide was extracted from Cryptoporus volvatus with a purity of over $97 \%$. Extraction and purity determination were done as previously described [9]. Briefly, air-dried fruiting bodies of C. volvatus (4800 g) were smashed and extracted with $90 \%$ ethanol 3 times under reflux for $1 \mathrm{~h}$. The solvent was removed under reduced pressure to yield $\sim 1240 \mathrm{~g}$ of the ethanol extract, which was then suspended in water and partitioned with petroleum ether, dichloromethane, ethyl acetate and $n$-butanol. The dichloromethane fraction (1000 g) was separated into eleven fractions (I-XI) by silica gel chromatography and eluted using dichloromethane-methanol $(1: 0-0: 1, \mathrm{v} / \mathrm{v})$. Fraction I $(8.8 \mathrm{~g})$ was then subjected to silica gel chromatography and eluted with petroleum etherethyl acetate (1:0-0:1, v/v) to obtain about $120 \mathrm{mg}$ EP.

\section{Virus strain}

The PDCoV CHN-HN-1601 strain (GenBank accession no: MG832584) was used in the study.

\section{Animals and experimental groups}

Ethical committee number for the study: CAU201908161. All animal experimental procedures were performed in accordance with protocols approved by the Institutional Animal Care and Use Committee (IACUC) of China Agricultural University. In vivo study of piglets was performed as previously described [20]. Studies have shown that piglets around one week of age are susceptible to PDCoV [6, 21]. Therefore, a total of 157 -day-old (Landrace $\times$ Large White) male piglets $(3.0 \pm 0.2 \mathrm{~kg})$ were obtained from a regular commercial farm in Tianjin, China. Prior to the start of the trial, no clinical signs of diarrhea or other diseases were observed in any of the piglets, and the rectal swabs were confirmed negative for the major porcine enteric viruses (PDCoV, porcine epidemic diarrhea virus (PEDV), transmissible gastroenteritis virus (TGEV), rotavirus) by Reverse transcription PCR. On day 0 , the piglets were randomly divided into the following three groups ( $n=5$ per group): (i) control group (CN), oral administration of $5 \mathrm{~mL} \mathrm{MEM} \mathrm{at} \mathrm{8:00}$ am on days 1-3; (ii) PDCoV group, oral administration 
of $5 \mathrm{~mL}$ MEM containing a total of $1 \times 10^{6} \mathrm{TCID}_{50}$ of the PDCoV CHN-HN-1601 strain at 8:00 am on day $1,5 \mathrm{~mL}$ MEM at 8:00 am on days 2-3; (iii) $\mathrm{PDCoV}+\mathrm{EP}$ group, oral administration of $5 \mathrm{~mL}$ MEM containing a total of $1 \times 10^{6} \mathrm{TCID}_{50}$ of the PDCoV CHN-HN-1601 strain and EP $(2.5 \mathrm{mg} / \mathrm{kg}$ body weight $)$ at $8: 00$ am on day $1,5 \mathrm{~mL}$ MEM containing EP $(2.5 \mathrm{mg} / \mathrm{kg}$ body weight $)$ on days $2-3$. On day 5 , piglets from each group were necropsied, and different tissue samples and blood samples were collected.

After infection, the piglets were observed daily for clinical signs, including vomiting, diarrhea and lethargy. Rectal temperature was measured twice daily, at 7:30 am and 7:30 pm on days 0-4. Fecal samples were collected from day 0 to day 4 to evaluate viral shedding. Severity of diarrhea was scored according to previously described with six criteria [22]: 1 , hard and formed pellets; 2 , nonformed pellets; 3 , soft feces; 4 , very soft and containing a small amount of water-like feces; 5 , semisolid containing more than half water-like feces; and 6, water-like feces. Piglets were considered to have severe diarrhea when the score was 5 or 6 .

\section{Differential blood leukocyte count}

The total peripheral blood leukocyte count and population distribution was determined using a semiautomated blood cell counter (Sysmex XN-1000 V, Japan). The proportions of neutrophils, lymphocytes and monocytes were expressed as a percentage of the total number of leukocytes.

\section{Histological and immunofluorescent staining}

Tissue samples were fixed in $10 \%$ formalin, and then dehydrated in graded ethanol, embedded in paraffin, cut in $5-\mu \mathrm{m}$ sections, and mounted onto glass slides. After the sections were deparaffinized, rehydrated, and stained with hematoxylin and eosin $(\mathrm{H} \& \mathrm{E})$, the slides were examined and analyzed with conventional light microscopy (Olympus IX71, Japan). Inflammation score was as previously described [22], with the modification including six criteria: epithelial integrity $(0=$ no change, $1=$ shedding of $<10$ epithelial cells per lesion, $2=$ shedding of 11-20 epithelial cells per lesion, $3=$ epithelial ulceration); central lacteal expansion $(0=$ no change, $1=$ mild, $2=$ moderate, $3=$ profound); leukocyte infiltration $(0 \leq 10$ leukocytes per field, $1=11-15$ leukocytes per field, $2=16-20$ leukocytes per field, $3 \geq 20$ leukocytes per field); submucosal edema $(0=$ no change, $1=$ mild, $2=$ moderate, $3=$ profound $) ;$ mucosal hyperemia $(0 \leq 10$ erythrocyte per field, $1=11-15$ erythrocyte per field, $2=16-20$ erythrocyte per field, $3 \geq 20$ erythrocyte per field); and Peyer's patch lesions $(0=$ no change, $1=$ mild, $2=$ moderate, $3=$ profound). The summation of the scores for each parameter provides an overall inflammation score for each sample, with a range of $0-18$. The typical features associated with each grade of inflammation were as follows: 0 , normal; $1-5$, mild inflammation; $6-12$, moderate inflammation; and 13-18, severe inflammation. No less than three separate sections of each sample were examined. The scoring was performed in a blinded manner. The total ileal score for each group was calculated as the average of the scores across all animals.

For immunofluorescent staining, the sections were permeabilized with $0.2 \%$ Triton X-100 in PBS for 10 min, and blocked with $1 \%$ bovine serum albumin (BSA) for $45 \mathrm{~min}$ at $37^{\circ} \mathrm{C}$. Subsequently, the sections were stained with anti-PDCoV monoclonal antibody (1:1000, Medgene, USA) overnight at $4{ }^{\circ} \mathrm{C}$. RBITC-conjugated goat antimouse IgG (1:200, Solarbio, China) was used as secondary antibody, and DAPI (Sigma-Aldrich, Germany) was used for nuclear staining. The slides were visualized and photographed using a Leica SP8 Laser Scanning confocal microscope (Leica Microsystems, Germany).

\section{RNA extraction and quantitative reverse transcription PCR (RT-qPCR)}

Total RNA from piglet feces and tissue samples was extracted using the BIOG RNA Stool Kit (Bio-generating, China) and the TRIzol reagent (Invitrogen, USA) according to the manufacturer's instructions, respectively. RNA was converted to cDNA using the HiFiScript cDNA Synthesis Kit (CoWin Biosciences, China). Viral RNA and cytokine mRNA were analyzed by RT-qPCR as previously described [9]. The specific primers crossing PDCoV ORF1a and ORF1b and the specific primers for porcine IL-1 $\beta$, IL- 6 , IL-12, TNF- $\alpha$, IFN- $\alpha$, IFN- $\beta$ and $\beta$-actin were listed in Table 1.

\section{Enzyme-linked immunosorbent assay (ELISA)}

Porcine-specific commercially available ELISA kits were used to measure the serum concentrations of TNF- $\alpha$ and IFN- $\gamma$ (R\&D Systems, USA).

\section{Flow cytometry}

Peripheral blood lymphocytes were isolated using Lymphocyte Separation Solution (TBD Science Inc., China) according to the manufacturer's instructions. The monoclonal antibodies used were as follows: mouse anti-pig CD3ع (clone P2G10, FITC-conjugated, 559582; BD Biosciences), mouse anti-pig CD4 $\alpha$ (clone 74-12-4, PerCPCy5.5-conjugated, 561474; BD Biosciences), mouse anti-human T-bet (clone O4-46, phycoerythrin [PE]conjugated, 561268; BD Biosciences), and mouse antipig IFN- $\gamma$ (clone P2G10, AlexaFluor 647-conjugated, 561480; BD Biosciences). The stained cells were analyzed on a FACScalibur ${ }^{\mathrm{TM}}$ flow cytometer (BD Biosciences), and 
Table 1 Sequences of the primers used for RT-qPCR.

\begin{tabular}{|c|c|c|}
\hline Primers name & Direction $^{a}$ & Sequence $\left(5^{\prime} \rightarrow 3^{\prime}\right)$ \\
\hline \multirow[t]{2}{*}{ PDCoV } & $\mathrm{F}$ & ACCTGTTTCCTTCGCCTTGA \\
\hline & $\mathrm{R}$ & ACAGCGTCTGGTTGAGTTCC \\
\hline \multirow[t]{2}{*}{$I L-1 \beta$} & $\mathrm{F}$ & AACGTGCAGTCTATGGAGT \\
\hline & $\mathrm{R}$ & GAACACCACTTCTCTCTTCA \\
\hline \multirow[t]{2}{*}{ IL-6 } & $\mathrm{F}$ & CTGGCAGAAAACA ACCTGAACC \\
\hline & $\mathrm{R}$ & TGATTCTCATCAAGCAGGTCTCC \\
\hline \multirow[t]{2}{*}{ IL-12 } & $\mathrm{F}$ & CGTGCCTCGGGCAATTATA \\
\hline & $\mathrm{R}$ & CGCAGGTGAGGTCGCTAGTT \\
\hline \multirow[t]{2}{*}{ TNF-a } & $\mathrm{F}$ & AACCTCAGATAAGCCCGTCG \\
\hline & $\mathrm{R}$ & ACCACCAGCTGGTTGTCTTT \\
\hline \multirow[t]{2}{*}{ IFN-a } & $\mathrm{F}$ & TCTCATGCACCAGAGCCA \\
\hline & $\mathrm{R}$ & CCTGGACCACAGAAGGGA \\
\hline \multirow[t]{2}{*}{ IFN- $\beta$} & $\mathrm{F}$ & AGTGCATCCTCCAAATCGCT \\
\hline & $\mathrm{R}$ & GCTCATGGAAAGAGCTGTGGT \\
\hline \multirow[t]{2}{*}{$\beta$-actin } & $\mathrm{F}$ & TGACTGACTACCTCATGAAGATCC \\
\hline & $\mathrm{R}$ & TCTCCTTAATGTCACGCACGATT \\
\hline
\end{tabular}

${ }^{\mathrm{a}} \mathrm{F}=$ forward; $\mathrm{R}=$ reverse.

data analysis was performed using FlowJo software (Tree Star).

\section{Terminal deoxynucleotidyl transferase-mediated dUTP} nick end labelling (TUNEL) assay

Paraffin-embedded intestinal tissues were evaluated using a TUNEL assay kit (Beyotime, China) for apoptosis according to the manufacturer's instructions and examined using a Leica SP8 Laser Scanning confocal microscope (Leica Microsystems, Germany).

\section{Small interfering RNA (siRNA) transfection}

Specific porcine p38 siRNA sequences were designed using the sequence of Sus scrofa p38 mRNA (GenBank Accession No. XM_003356616.1) and synthesized by Genepharma (Shanghai, China). NC siRNA (5'-UUC UCCGAACGUGUCACGUTT-3') was purchased from Genepharma. The p38 siRNA sequences were as follows: 5'-CCGAGGUCUCAAGUAUAUATT-3' (\#1), 5'-GGG CAGAUCUGAACAACAUTT-3' (\#2) and 5'-GCAGGA GCUGAACAAGACATT-3' (\#3). The siRNAs were transfected using HiPerFect Transfection Reagent (Giagen, Germany) at a final concentration of $60 \mathrm{nM}$ according to the manufacturer's instructions. After $24 \mathrm{~h}$, the efficiency of the siRNA was characterized by Western blot.

\section{Cell culture}

LLC-PK1 cells (ATCC CL-101) were obtained from the American Type Culture Collection (ATCC) and cultured in MEM (Gibco, USA) supplemented with
1\% antibiotic-antimycotic (Gibco, USA), 1\% HEPES (Gibco, USA), 1\% MEM non-essential amino acids solution (NEAA) (Gibco, USA) and 10\% heat-inactivated fetal bovine serum (FBS) (Gibco, Australia) at $37{ }^{\circ} \mathrm{C}$ with $5 \% \mathrm{CO}_{2}$. LLC-PK1 cells grown in 6-well plates were transfected with p38 siRNA \#1 or NC siRNA. At $24 \mathrm{~h}$ post-transfection, the cells were mock-infected or infected with PDCoV $(\mathrm{MOI}=2)$ in the absence or presence of EP $(150 \mu \mathrm{M})$. After PDCoV adsorption for $1 \mathrm{~h}$, the cells were further cultured in fresh medium in the absence or presence of EP $(150 \mu \mathrm{M})$. The cells were harvested for subsequent analysis at 24 hours post-infection (hpi).

\section{Western blot}

Intestinal tissue sample weighing $0.1 \mathrm{~g}$ was lysed in $1 \mathrm{~mL}$ radioimmunoprecipitation assay (RIPA) lysis buffer (CoWin Biosciences, China) with $1 \mathrm{mM}$ phenylmethyl sulfonyl fluoride (PMSF, Beyotime, China) and $20 \mu \mathrm{M} \mathrm{NaF}$ for $10 \mathrm{~min}$. The tissue lysates were centrifuged at $12000 \times g$ for $15 \mathrm{~min}$ at $4{ }^{\circ} \mathrm{C}$ to remove insoluble material, and protein concentration of the resulting supernatants was quantified using a BCA protein assay kit (Thermo Fisher Scientific, USA). The LLC-PK1 cell monolayers were lysed in the same lysate for $10 \mathrm{~min}$ and protein concentration was quantified using the same method. An equal amount of protein samples $(20 \mu \mathrm{g})$ was used for Western blot assay. Primary antibodies were anti-PDCoV N (1:5, provided by Professor Pinghuang Liu, China Agricultural University), anti-phospho-NF- $\mathrm{B}$ p65, anti-phospho-p38 (1:500, Cell Signaling Technology, USA), anti-phospho-IкB $\alpha$ (1:200, Cell Signaling Technol-

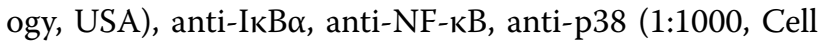
Signaling Technology, USA), anti-claudin-1, anti-occludin, anti-ZO-1, anti-Bax, anti-Bcl-2 (1:1000, Abcam, UK), anti-cleaved caspase-3, anti-caspase-3 (1:500, Abcam, UK) and anti- $\beta$-actin (1:1000, ProteinTech Group, USA). Horseradish peroxidase conjugated to AffiniPure goat anti-mouse IgG (1:5000, ProteinTech Group, USA) or goat anti-rabbit IgG (1:5000, ProteinTech Group, USA) were used as secondary antibodies.

\section{Statistical analysis}

Statistical analysis was performed using IBM SPSS Statistics 25 software (IBM, USA). Differences between means were compared using Tukey's honestly significant difference post-hoc test. The data were visualized using GraphPad Prism 7 software (GraphPad Software, USA) and expressed as mean \pm SEM. The statistically significant differences were set at $P<0.05$. ${ }^{*} P<0.05$; ${ }^{* *} P<0.01$; *** $P<0.001$. 


\section{Results}

\section{Ergosterol peroxide alleviated PDCoV-associated} pathological manifestation in piglets

Before infection, rectal temperature was within the normal range $\left(39.27{ }^{\circ} \mathrm{C} \pm 0.13{ }^{\circ} \mathrm{C}\right)$ for all the three groups (Figure 1A). However, on $3 \mathrm{dpi}$, the rectal temperature of group PDCoV increased to $39.76{ }^{\circ} \mathrm{C} \pm 0.16{ }^{\circ} \mathrm{C}$, which was significantly higher than that of groups $\mathrm{CN}(P<0.001)$ and $\mathrm{PDCoV}+\mathrm{EP}(P=0.009)$, and this trend continued until 4 dpi. No significant differences were observed between groups $\mathrm{CN}$ and $\mathrm{PDCoV}+\mathrm{EP}$.

Following PDCoV infection, all piglets in group PDCoV exhibited diarrhea lasting to $4 \mathrm{dpi}$, especially on $3 \mathrm{dpi}$, presenting watery diarrhea (Figure 1B). Administration of EP reduced diarrhea incidence to a level similar to that of group $\mathrm{CN}$. Besides, only the piglets in group PDCoV exhibited lethargy and anorexia on 2 days postinfection (dpi) to $4 \mathrm{dpi}$, and two of them vomited on 2 dpi to 3 dpi. Post-mortem examination showed that the small intestines of group PDCoV were clearly transparent, thin-walled, and a large amount of yellow fluid accumulated in the intestinal lumen (Figure 1C). No lesions were observed in groups $\mathrm{CN}$ and $\mathrm{PDCoV}+\mathrm{EP}$ at necropsy (Figure 1C). Histopathologic analysis revealed that the jejunum and ileum of group PDCoV exhibited obvious pathological changes (Figure 1D). Lesions of jejunum showed intestinal villus blunting and rupture, enterocyte attenuation, intestinal epithelial cell shedding. Lesions of ileum showed mucosal layer edema, atrophy of intestinal glands and basement membrane rupture. In comparison, only slight changes were detected in group PDCoV $+\mathrm{EP}$ (Figure 1D), presenting mild hyperemia in the jejunum and ileum. No lesions were seen in group $\mathrm{CN}$ (Figure 1D).

PDCoV infection had no significant effects on the total peripheral blood leukocyte count (Figure 1E), and the percentage of neutrophils (Figure 1F), lymphocytes (Figure 1G) and monocytes (Figure 1H) compared with group $\mathrm{CN}$.

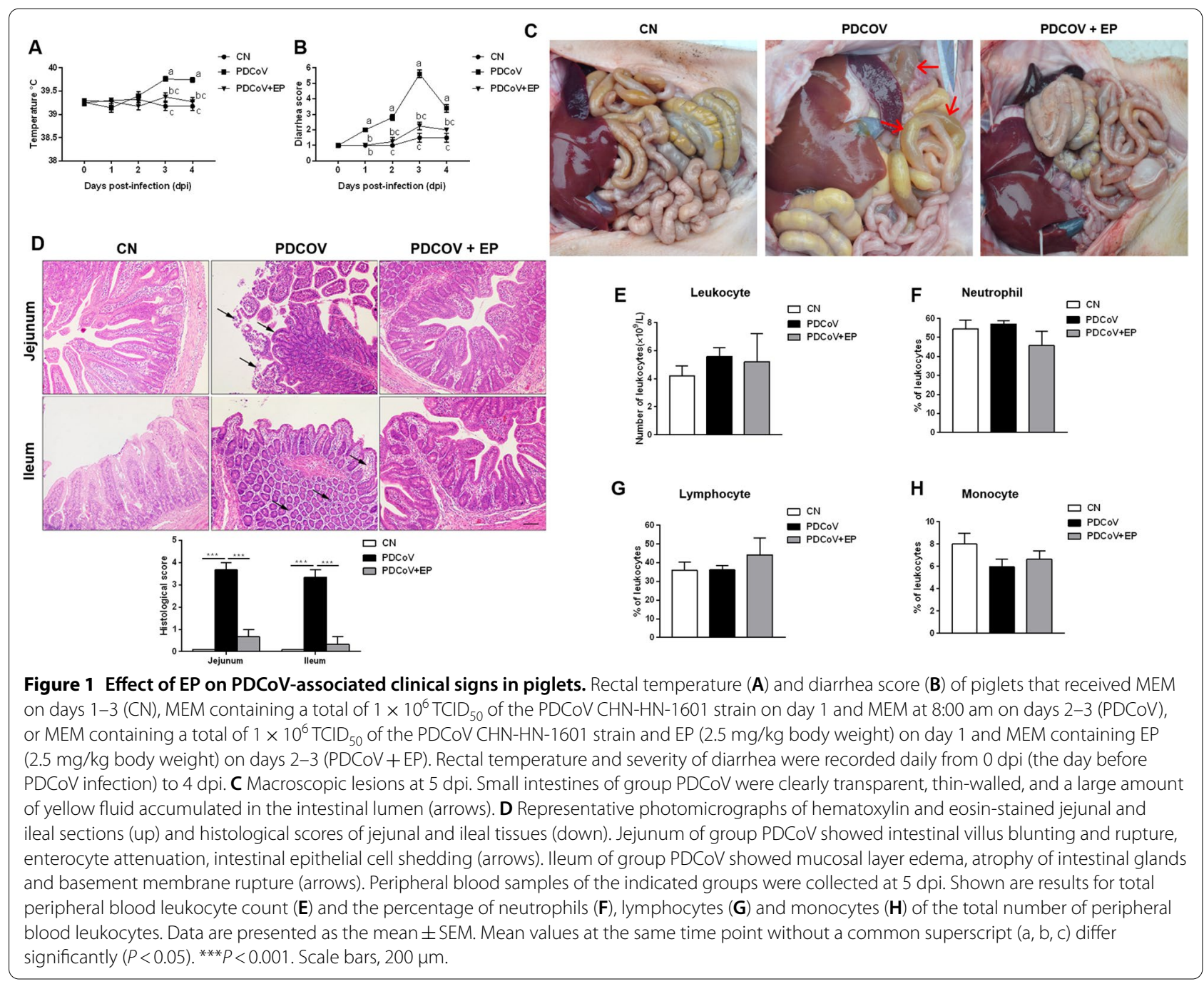


Administration of EP inhibited PDCoV replication in piglets To examine the inhibitory effect of EP on PDCoV replication in vivo, we determined the fecal viral shedding and virus distribution in piglets. Compared with group PDCoV, group PDCoV+EP had lower levels of viral RNA in the fecal samples (Figure 2A). Administration of EP also reduced PDCoV viral load in various tissues (Figure $2 \mathrm{~B}$ ). The relative viral RNA levels in the liver $(P=0.010)$, spleen $(P<0.001)$, lung $(P<0.001)$, kidney $(P<0.001)$, duodenum $(P<0.001)$, jejunum $(P<0.001)$, ileum $(P<0.001)$, cecum $(P<0.001)$, colon $(P=0.015)$, and mesenteric lymph nodes $(\mathrm{MLN})(P<0.001)$ in group $\mathrm{PDCoV}+\mathrm{EP}$ were significantly lower than those in group PDCoV (Figure 2B). No PDCoV RNA was detected in group $\mathrm{CN}$. These results were further confirmed in the jejunum and ileum by Western blot analysis (Figure $2 \mathrm{C}$ ) and fluorescence imaging (Figure 2D). Western blot analysis showed that the PDCoV N protein expression in the jejunum and ileum of group PDCoV $+\mathrm{EP}$ was remarkably lower than that of group PDCoV (Figure $2 \mathrm{C}$ ). Fluorescence imaging of the jejunum and ileum demonstrated that numerous $\mathrm{PDCoV}$ antigen-positive cells were observed in group PDCoV, while PDCoV antigen-positive cells were hardly observed in group PDCoV + EP (Figure 2D).

\section{Administration of EP suppressed PDCoV-induced apoptosis in the small intestine}

A great number of TUNEL-positive cells were detected in the jejunum and ileum of group PDCoV (Figure 3A), indicating that plentiful immune cells or enterocytes underwent apoptosis. However, only few TUNEL-positive cells were occasionally detected in groups $\mathrm{CN}$ and $\mathrm{PDCoV}+\mathrm{EP}$. These results were further confirmed by the analysis of the main apoptotic executioner caspase-3, pro-apoptotic Bax and anti-apoptotic Bcl-2 protein expression in the small intestine of piglets. PDCoV infection increased the expressions of cleaved caspase-3 (Figures $3 \mathrm{~B}, \mathrm{C} ; P=0.003$ and $P=0.046$, respectively) and Bax (Figures $3 \mathrm{~B}, \mathrm{E} ; P=0.026$ and $P=0.003$, respectively), and decreased expression of Bcl-2 (Figures 3B, F; $P=0.011$ and $P=0.020$, respectively) in the jejunum and ileum compared with group $\mathrm{CN}$. These changes were attenuated by oral administration of EP. Lower expressions of cleaved caspase-3 (Figures 3B, C; $P=0.015$ and $P=0.044$, respectively) and Bax (Figures 3B, E; $P=0.033$ and

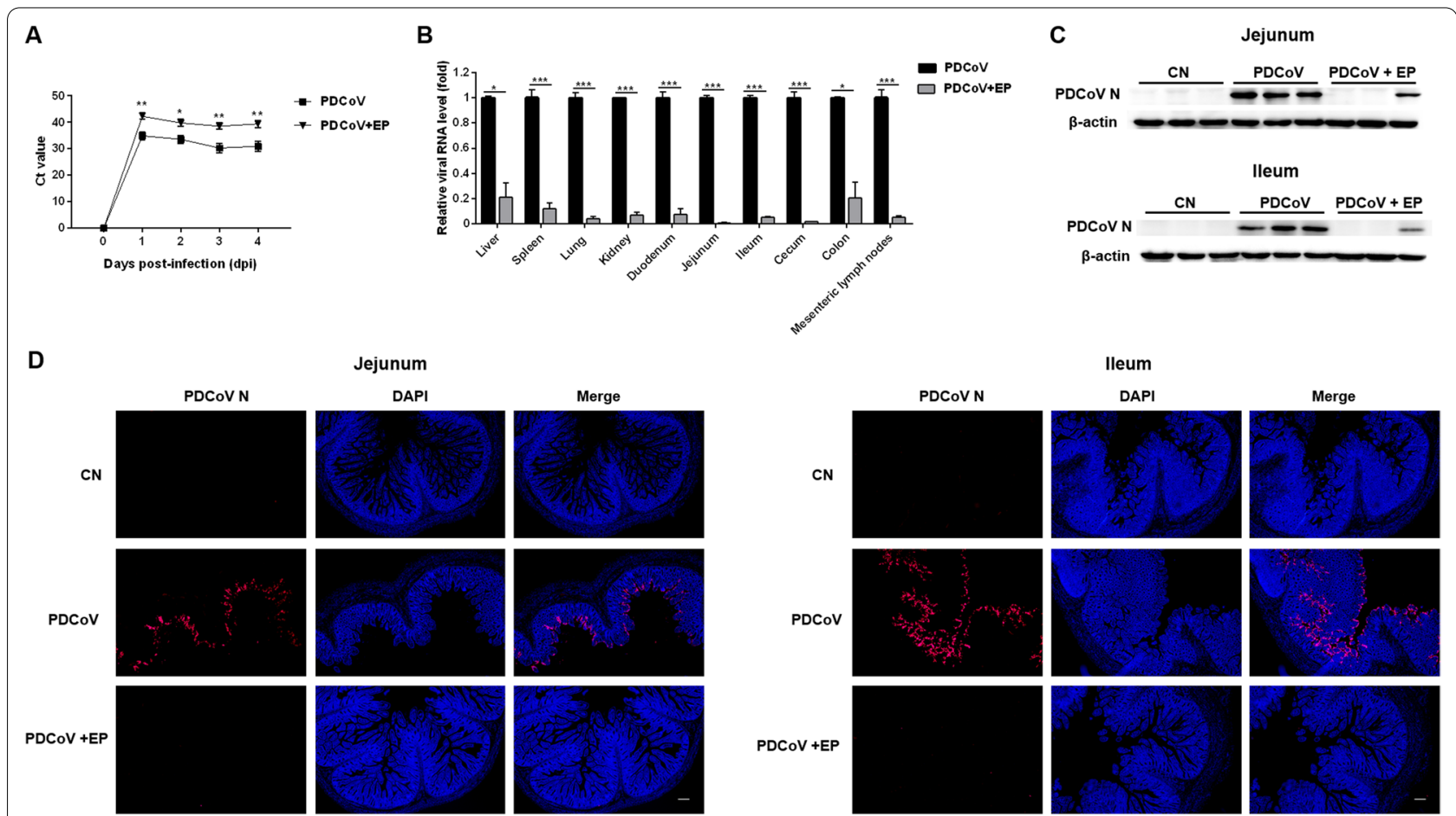

Figure 2 Antiviral effect of EP on PDCoV replication in piglets. A Effect of EP on fecal viral shedding. Fecal samples of the indicated groups were collected from $0 \mathrm{dpi}$ (the day before PDCoV infection) to $4 \mathrm{dpi}$. The relative viral RNA level in the fecal samples was analyzed by RT-qPCR. B Effect of EP on virus distribution. Different tissue samples of the indicated groups were collected at 5 dpi. The relative viral RNA level in the collected samples was analyzed by RT-qPCR. C Western blot analysis of proteins from jejunal and ileal tissues probed with the anti-PDCoV N antibody. The loading was normalized with $\beta$-actin. D Fluorescence imaging of jejunal and ileal tissues. Red fluorescence represents the PDCoV distribution, and blue fluorescence represents the nuclear distribution. Scale bars, $20 \mu \mathrm{m}$. Data are presented as the mean \pm SEM. ${ }^{*} P<0.05 ;{ }^{* *} P<0.01 ;{ }^{* * *} P<0.001$. 


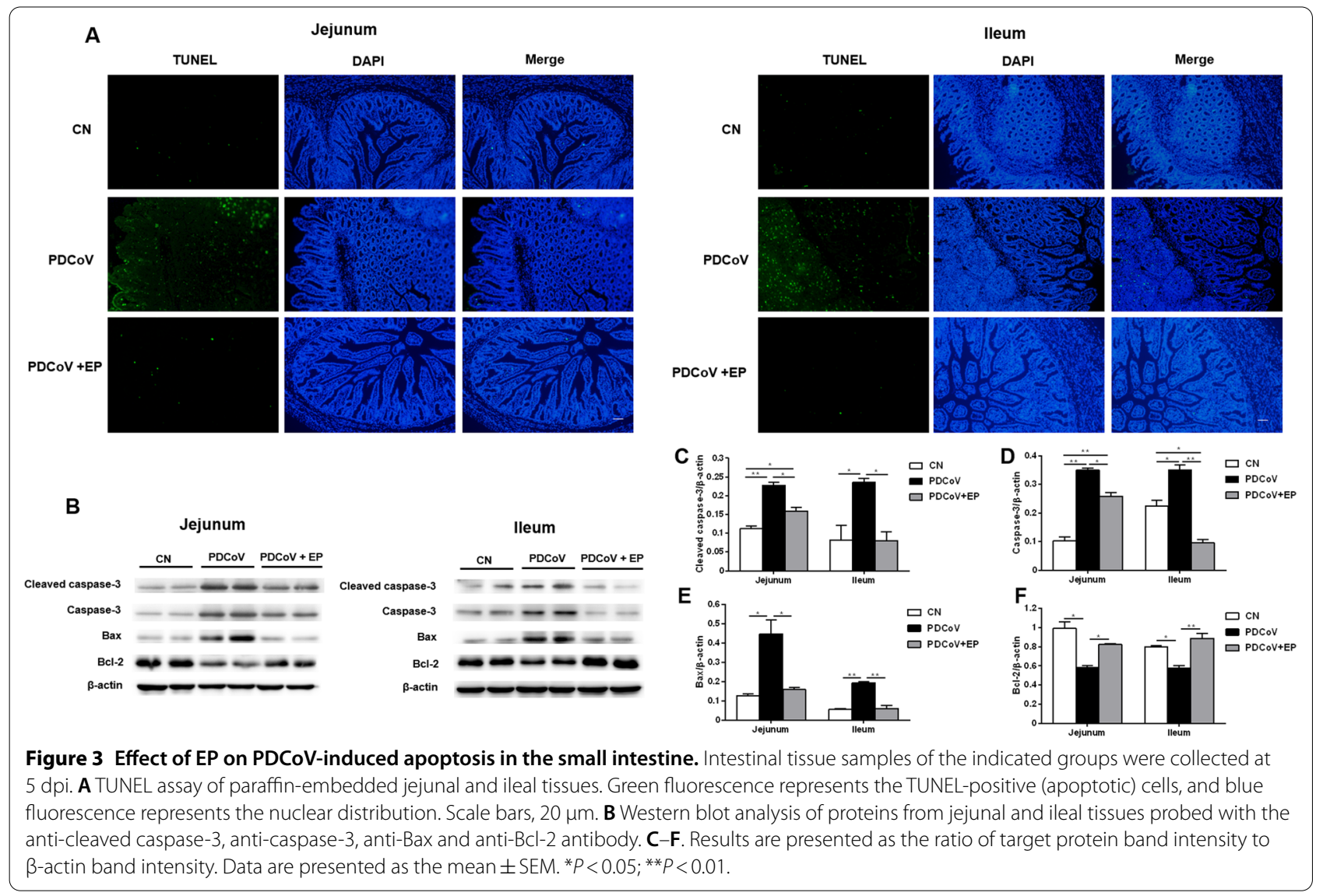

$P=0.004$, respectively), and higher expression of Bcl-2 (Figures 3B, F; $P=0.047$ and $P=0.008$, respectively) were observed in the jejunum and ileum of group PDCoV $+E P$ compared with group PDCoV.

\section{Administration of EP enhanced claudin-1 and ZO-1 expression in the small intestine}

To detect the impact of PDCoV infection on TJ proteins and the regulation of EP on them, the expressions of claudin-1, occludin, and ZO-1 in the small intestine were analyzed by Western blot. The claudin-1 expression in the jejunum was higher in group $\mathrm{PDCoV}+\mathrm{EP}$ than in groups $\mathrm{CN}$ and $\mathrm{PDCoV}$ (Figures $4 \mathrm{~A}, \mathrm{~B} ; \mathrm{P}=0.022$ and $P=0.025$, respectively). No differences were found in the jejunum and ileum between groups $\mathrm{CN}$ and PDCoV. The occludin expression in the jejunum and ileum had no difference among three groups (Figures 4A, C). The ZO-1 expression in the jejunum and ileum was lower in group $\mathrm{PDCoV}$ than in group $\mathrm{CN}$ (Figures 4A, D; $P=0.044$ and $P=0.034$, respectively). Compared with group $\mathrm{PDCoV}$, administration of EP increased the expression of ZO-1 in the jejunum and ileum of group PDCoV +EP (Figures $4 \mathrm{~A}, \mathrm{D} ; P=0.002$ and $P=0.030$, respectively).
PDCoV infection increased the percentage of $\mathrm{CD}^{+} \mathrm{T}$ cells but decreased the percentages of $\mathrm{CD}^{+}{ }^{+}$-bet $^{+} \mathrm{T}$ cells and $\mathrm{CD}^{+}{ }^{+} \mathrm{T}^{-b e t^{+}}{ }^{+} \mathrm{FN}{ }^{+} \mathrm{T}$ cells in peripheral blood

We assessed changes in the proportion of $\mathrm{CD} 4^{+} \mathrm{T}$ cells in peripheral blood by flow cytometry. An increase in the percentage of $\mathrm{CD} 4^{+} \mathrm{T}$ cells (Figure $5 \mathrm{~A} ; P=0.001$ ) was observed in group PDCoV compared with group $\mathrm{CN}$. The percentage of $\mathrm{CD}^{+}{ }^{+}$T-bet ${ }^{+} \mathrm{T}$ cells (Figure $5 \mathrm{C} ; P=0.018$ ) and $\mathrm{CD}^{+}{ }^{+} \mathrm{T}_{\text {-bet }}{ }^{+} \mathrm{IFN}^{+}{ }^{+} \mathrm{T}$ cells (Figure $5 \mathrm{D} ; P=0.030$ ) were lower in group PDCoV than in group $\mathrm{CN}$. No significant difference in the proportion of $\mathrm{CD}^{+} \mathrm{IFN \gamma}^{+} \mathrm{T}$ cells was observed among three groups (Figure 5B).

\section{Administration of EP suppressed PDCoV-induced} pro-inflammatory cytokines but promotes type I interferon Elevation of serum TNF- $\alpha$ concentration was seen in group PDCoV (Figure 6A; $P=0.008$ ) but not in group $\mathrm{PDCoV}+\mathrm{EP}$ compared with group $\mathrm{CN}$. PDCoV infection increased the amount of IFN- $\gamma$ compared with group $\mathrm{CN}$ (Figure 6B; $P=0.041$ ). No differences in the serum concentrations of IFN- $\gamma$ were observed between groups PDCoV and PDCoV + EP. Increases in the mRNA 
A
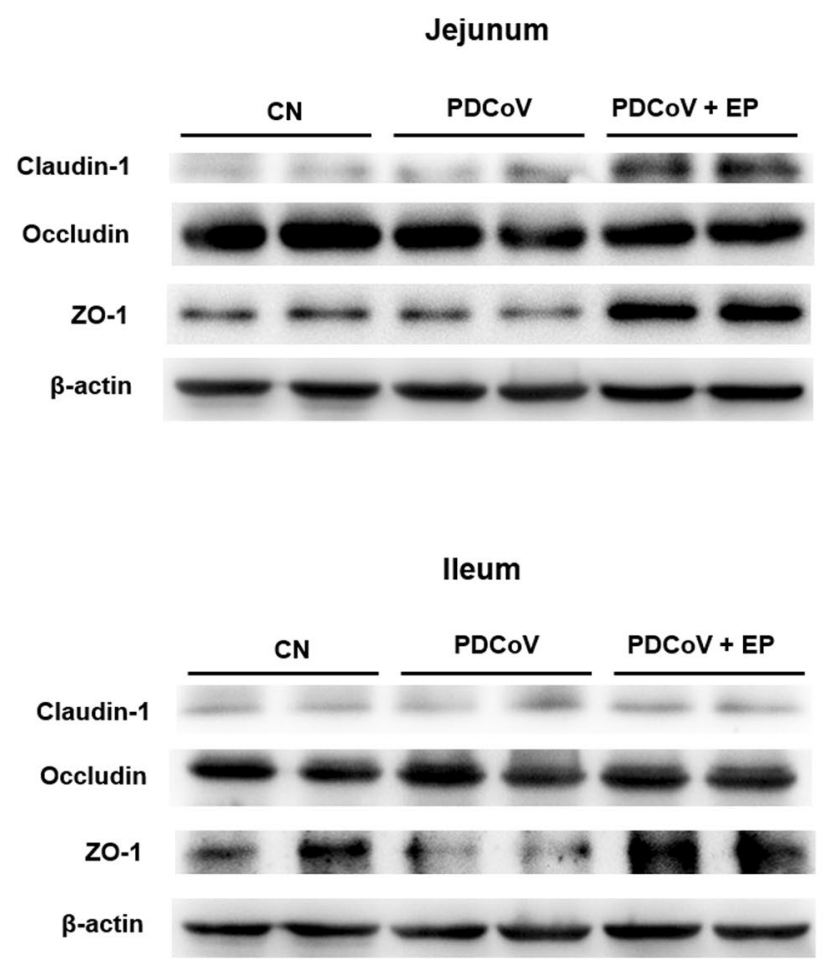

B

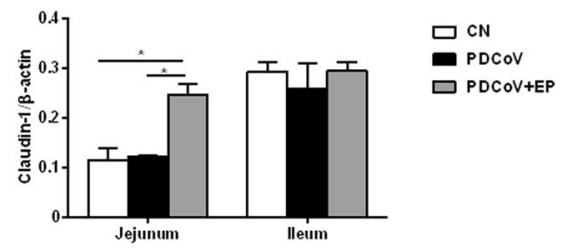

C

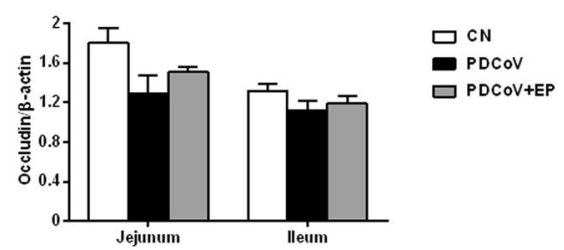

D

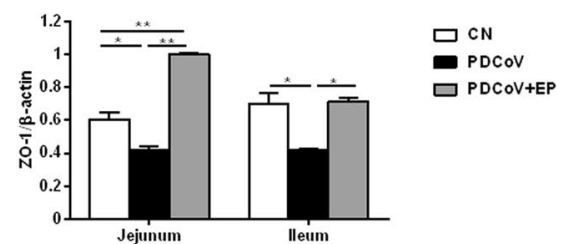

Figure 4 Effect of EP on tight junction proteins in the small intestine. A Western blot analysis of proteins from jejunal and ileal tissues probed with the anti-claudin-1, anti-occludin and anti-ZO-1 antibody. B-D. Results are presented as the ratio of target protein band intensity to the intensity of the $\beta$-actin band. Data are presented as the mean \pm SEM. ${ }^{*} P<0.05 ;{ }^{*} P<0.01$.

expressions of ileal IL-1 $\beta$ (Figure 6C; $P=0.034$ ), jejunal IL-12 (Figure 6E; $P=0.010$ ), and ileal and jejunal TNF- $\alpha$ (Figure 6F; $P=0.003$ and $P<0.001$, respectively) were observed in group PDCoV but not in group PDCoV+EP, compared with group $\mathrm{CN}$. INF- $\alpha$ (Figure 6G; $P=0.030$ and $P=0.003$, respectively) and IFN- $\beta$ (Figure $6 \mathrm{H}$; $P=0.019$ and $P=0.017$, respectively) mRNA expressions were upregulated in the jejunum and ileum of group PDCoV compared with group CN. Moreover, INF- $\alpha$ (Figure 6G; $P=0.001$ and $P=0.012$, respectively) and IFN- $\beta$ (Figure $6 \mathrm{H} ; P<0.001$ and $P=0.022$, respectively) mRNA expressions were higher in the jejunum and ileum of group PDCoV + EP than that of group PDCoV. No differences in IL-6 mRNA expression were found in the small intestine among three groups (Figure 6D).

\section{Administration of EP suppresses PDCoV-induced activation} of IкBa, NF-кB p65 and p38 in the small intestine

Western blot analysis demonstrated that $\mathrm{PDCoV}$ infection resulted in an increase in the expression of $\mathrm{p}-\mathrm{I} \kappa \mathrm{B} \alpha$ (Figures 7A, B; $P=0.006$ and $P=0.001$, respectively), p-NF-kB p65 (Figures 7A, D; $P=0.004$ and $P=0.007$, respectively) and p-p38 (Figures $7 \mathrm{~A}, \mathrm{~F} ; \mathrm{P}=0.005$ and $P=0.001$, respectively) in the jejunum and ileum compared with group $\mathrm{CN}$. However, the phosphorylation levels of IкB $\alpha$ (Figures 7A, B; $P=0.004$ and $P=0.007$, respectively), NF-kB p65 (Figures 7A, D; $P=0.003$ and $P=0.049$, respectively) and p38 (Figures 7A, F; $P=0.009$ and $P=0.033$, respectively) in the jejunum and ileum of group $\mathrm{PDCoV}+\mathrm{EP}$ were obviously lower than those of group PDCoV, indicating that EP can alleviate the activation of the NF- $\mathrm{kB}$ and $\mathrm{p} 38 / \mathrm{MAPK}$ signaling pathways caused by PDCoV.

\section{EP inhibits PDCoV replication and alleviates} PDCoV-induced apoptosis via p38/MAPK signaling pathway

We used siRNA-mediated knockdown to further address the role of p38 in inhibiting PDCoV replication and alleviating PDCoV-induced apoptosis by EP in LLC-PK1 cells. The siRNA targeting p38 apparently reduced the expression of p38 (Figure $8 \mathrm{~A}$ ), and p38 siRNA \#1 was used for subsequent experiments. Compared with the uninfected cells, cells infected with PDCoV only had higher expression levels of p-p38 (Figures 8B, C), cleaved-caspase-3 (Figures 8B, E) and bax (Figures 8B, G). However, the expression levels of 


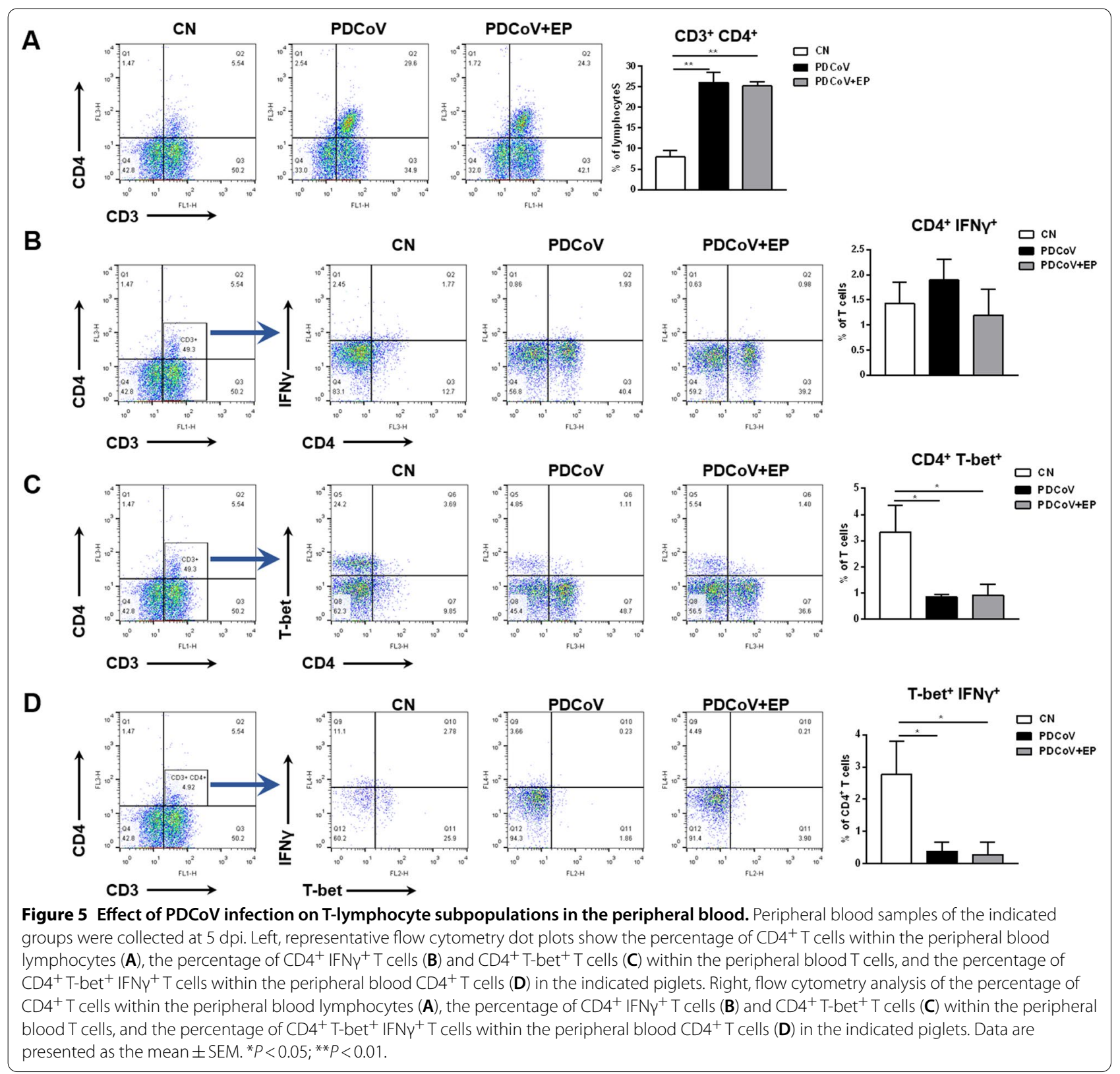

cleaved-caspase-3 (Figures 8B, E), bax (Figures 8B, G) and PDCoV N (Figures 8B, I) in cells transfected with p38 siRNA before PDCoV infection were lower than those of cells infected with PDCoV only. These results suggest that PDCoV may activate p38 to facilitate its replication and induce apoptosis. Compared with cells infected with PDCoV only, cells infected with PDCoV in the presence of EP showed significantly lower expression of PDCoV N (Figures 8B, I), p-p38 (Figures 8B, C), cleaved-caspase-3 (Figures 8B, E) and bax (Figures 8B,
G), implying that EP may inhibit PDCoV replication and alleviate PDCoV-induced apoptosis by suppressing p38 activation caused by PDCoV.

\section{Discussion}

As PDCoV spreads around the world, placing strain on the economy and public health, the prevention and treatment of PDCoV is clearly important. Until now, there has been no report about PDCoV vaccines, and only few reports about anti-PDCoV drugs. Lithium chloride and diammonium glycyrrhizinate (DG) were reported 

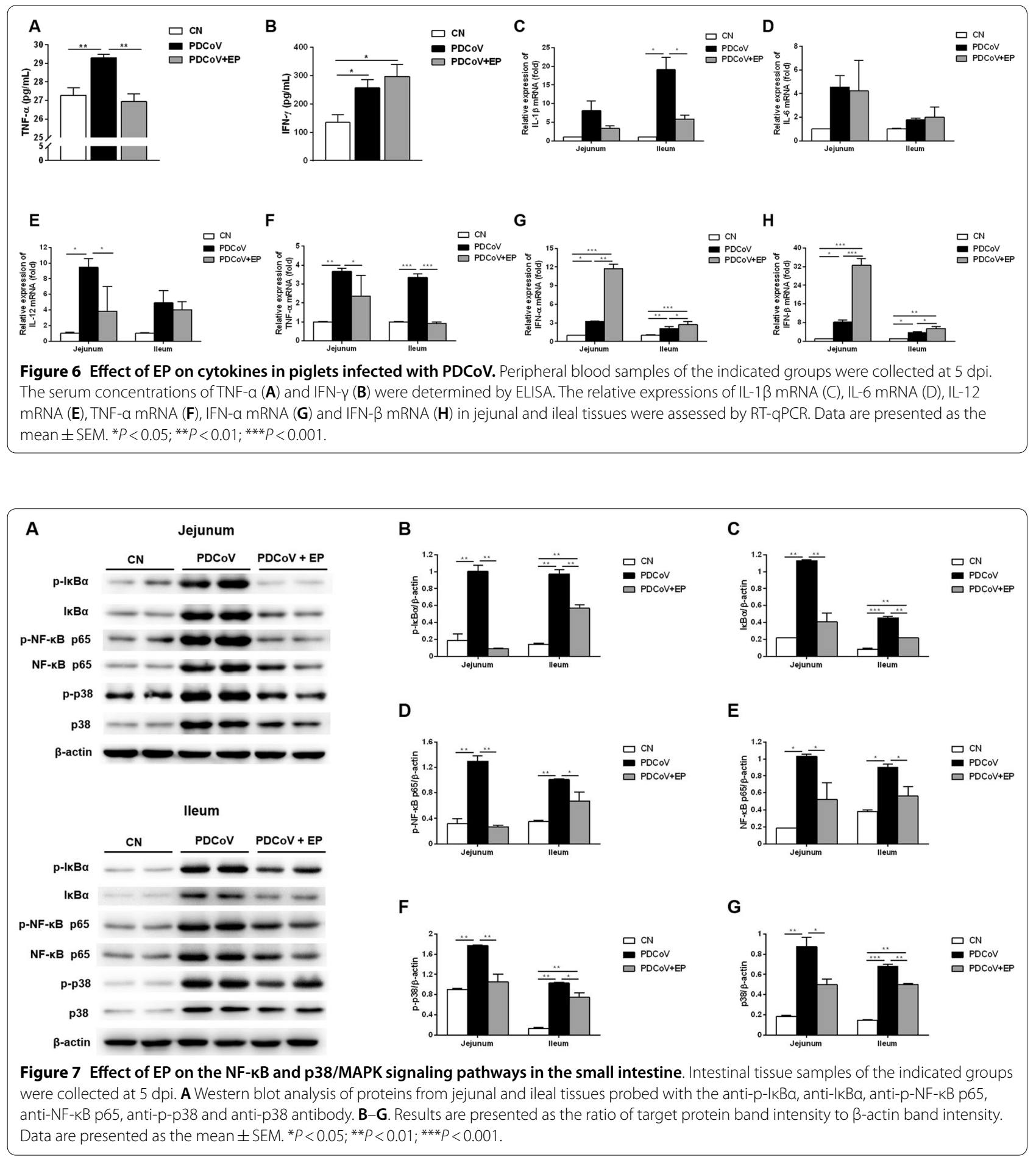

to inhibit PDCoV replication at the early stage in LLCPK1 cells, and DG also inhibited virus attachment to the cells [23]. Rhodanine derivative LJ001 showed antiviral activity against PDCoV infection in ST cells [24]. Besides, $\mathrm{PDCoV}$ was shown to be susceptible to remdesivir treatment in Huh7 cells [25]. However, there has been no record of effective drugs for the treatment of PDCoV infection in vivo. Our previous study revealed that EP from the mushroom $C$. volvatus has efficient anti-PDCoV properties in LLC-PK1 and ST cells, targeting multiple 


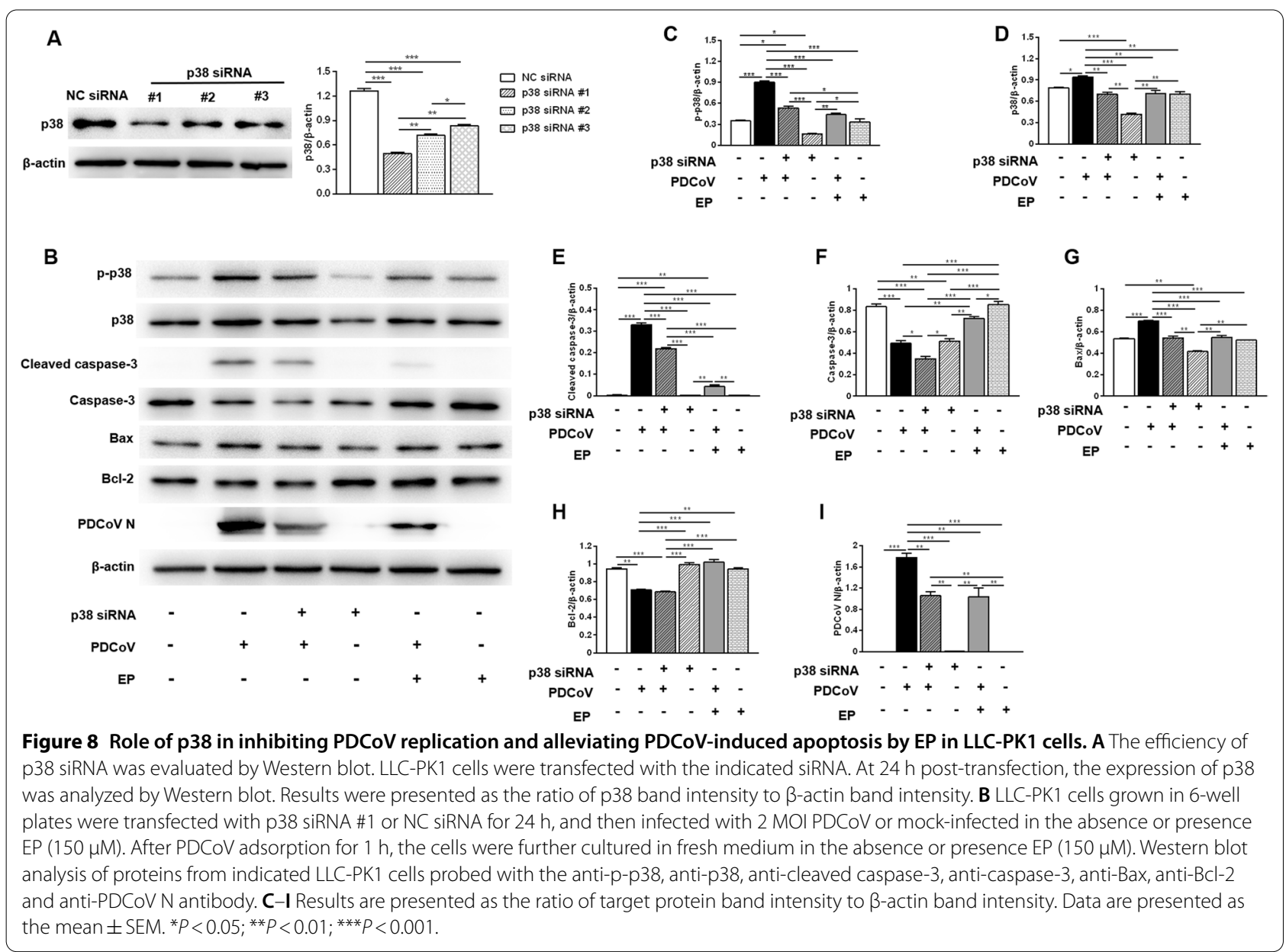

stages of the PDCoV life cycle, including attachment, entry, and the early and middle stages of the post-entry stage, and even has a virucidal effect against PDCoV [9]. The present results demonstrated that oral administration of EP diminished the pathological manifestation caused by PDCoV infection and reduced viral load in piglets, showing the promise of EP in the treatment of $\mathrm{PDCoV}$, and making up the vacancy in clinical research on anti-PDCOV drugs.

The intestinal barrier acts as a semi-permeable barrier allowing the absorption of different molecules, such as water or nutrients [26], and plays a leading role in regulating the immune system through recognizing microorganisms [27]. It is maintained by two key mechanisms: epithelial cell homeostasis to regulate cell numbers forming the barrier and homotypic junctional complexes to regulate paracellular permeability across the barrier [28]. Intestinal epithelial cell homeostasis is established by equilibrium between cell proliferation and cell death. Dysregulated or excessive epithelial cell death is associated with the destruction of barrier integrity and leakage across the paracellular space. Histopathologic analysis revealed that the jejunal and ileal tissues infected with PDCoV exhibited enterocyte attenuation. The massive loss of enterocytes destroyed the intestinal barrier, hampered the absorption and digestion of nutrients and electrolytes in the small intestines, causing malabsorptive and dyspepsia diarrhea that consequently led to fatal dehydration in piglets. Next, we found that PDCoV infection resulted in severe apoptosis in the jejunum and ileum. This is consistent with one previous study on another CoV, PEDV, causing intestinal apoptosis [29], but contrary to another study which showed that PDCoV did not induce apoptosis in the infected intestinal enterocytes in vivo [30]. The difference in results may be due to the age of piglets and the time of necropsy. Administration of EP reduced PDCoV-induced apoptosis and was beneficial to maintain the integrity intestinal barrier.

TJ proteins connect the intestinal epithelial cells and regulate the paracellular permeability [28]. The destruction of these proteins may cause the damage of intestinal barrier. One previous study showed that impaired 
TJs in intestinal epithelium of patients with human immunodeficiency virus contributed to intestinal barrier dysfunction, resulting in severe, chronic diarrhea [31]. Administration of EP recovered PDCoV-decreased jejunal and ileal ZO-1 expression and improved jejunal claudin-1 expression. Taken together, EP's protection of intestine from PDCoV infection may be attributed to its ability to inhibit apoptosis and avoid TJ protein loss.

During viral infection, $\mathrm{CD} 4^{+} \mathrm{T}$ cells can provide effective immunity protection through direct effector function and by helping other leukocytes to maximize the protective activities [12]. Our present results demonstrated that the proportion of $\mathrm{CD} 4^{+} \mathrm{T}$ cells in peripheral blood increased after PDCoV infection, which is similar to PEDV infection [32]. Besides, PDCoV infection led to a reduction in the percentage of $\mathrm{CD} 4^{+} \mathrm{T}^{- \text {bet }^{+}} \mathrm{IFN \gamma} \gamma^{+} \mathrm{T}$ cells in peripheral blood. To our knowledge, this is the first report to prove the impact of PDCoV infection on $\mathrm{CD}^{+} \mathrm{T}$ cells, which provides further insights for understanding the immune response to PDCoV.

Cytokines are crucial in immune defense and pathogenesis during viral infections. Administration of EP promoted type I interferon expression, promoting its antiviral activity against PDCoV. In addition, PDCoV infection increased TNF- $\alpha$ concentration in the serum and the mRNA levels of IL- $1 \beta$, IL- 12 and TNF- $\alpha$ in the small intestine. These increased pro-inflammatory cytokines may coordinate and activate adaptive immune responses. However, their excessive release may also mediate immunopathology. For example, acute lung injury caused by severe acute respiratory syndrome coronavirus (SARS-CoV) or Middle Eastern respiratory syndrome coronavirus (MERS-CoV) infection is closely related to the elevated pro-inflammatory cytokine responses, such as IL-6, IL-12 and TNF- $\alpha$ [33]. Intensive immunosuppression therapy with high dose glucocorticoids, followed by an IL- 6 receptor antagonist reduced the mortality as a result of severe acute respiratory syndrome coronavirus 2 (SARS-CoV-2)-associated cytokine storm syndrome [34]. Here, administration of EP reduced PDCoV-induced pro-inflammatory cytokines to similar levels as group $\mathrm{CN}$, implying that EP has an immunomodulatory effect during PDCoV infection. NF- $\mathrm{KB}$ is one of the key transcription factors that regulate the production of pro-inflammatory cytokines. Administration of EP suppressed PDCoV-induced activation of NF-kB signaling pathway, which in turn reduced the amount of pro-inflammatory cytokines.

Virus relies on the host cell machinery for effective replication. MAPK signaling pathways are reported to be manipulated by $\mathrm{CoVs}$ to facilitate their replication. For example, inhibition of p38 or JNK1/2 resulted in a significant reduction in PEDV RNA synthesis, protein expression and progeny release [35]. In addition, the p38/MAPK signaling pathway can convert extracellular stimuli into a wide range of cellular responses, including apoptosis [19]. Here, we found that knockdown of p38 decreased PDCoV replication and alleviated PDCoVinduced apoptosis, implying that $\mathrm{PDCoV}$ might activate the p38/MAPK signaling pathway to facilitate its replication and induce apoptosis. EP decreased PDCoV-induced activation of $\mathrm{p} 38$, which may contribute to its inhibition on $\mathrm{PDCoV}$ replication and alleviation of apoptosis induced by PDCoV.

In conclusion, our study in a piglet model indicates that oral administration of EP confers a degree of protection against $\mathrm{PDCoV}$ infection, providing potential insights for the clinical prevention and treatment of PDCoV.

\section{Abbreviations}

PDCoV: Porcine deltacoronavirus; CoV: Coronavirus; EP: Ergosterol peroxide; TJ: Tight junction; NF-kB: Nuclear factor-kB; IKB: Inhibitor of NF-kB; IL: Interleukin; TNF-a: Tumor necrosis factor-a; IFN: Interferon; TCID 50 : 50\% Tissue culture infection dose; MAPK: Mitogen-activated protein kinase; JNK: Janus kinase; PEDV: Porcine epidemic diarrhea virus; RT-qPCR: Quantitative reverse transcription PCR; ELISA: Enzyme-linked immunosorbent assay; TUNEL: Terminal deoxynucleotidyl transferase-mediated dUTP nick end labelling.

\section{Acknowledgements}

This work was supported by the National Key R\&D Program of China (Grant Number 2017YFD0502200). We would like to thank Professor Hanchun Yang and Professor Pinghuang Liu of China Agricultural University for providing the PDCoV CHN-HN-1601 strain and anti-PDCoV N monoclonal antibody.

\section{Authors' contributions}

$\mathrm{CD}$ and $\mathrm{YL}$ performed the experiments; JW and JZ provided technical and material supports; CD and YL collected and analyzed the data; CD wrote the article; JS, ZH, and JW designed and supervised the study. All authors read and approved the final manuscript.

\section{Declarations}

Ethics approval and consent to participate

All the experimental animals in this study were treated in strict accordance with the Guidelines for Laboratory Animal Use and Care from the Chinese Center for Disease Control and Prevention and the Rules for Medical Laboratory Animals (1998) from the Chinese Ministry of Health, under protocol CAU20190816-1, which was approved by the Animal Ethics Committee of the China Agricultural University. All animals were euthanized under pentobarbital sodium anesthesia and every effort was made to alleviate pain.

\section{Competing interests}

The authors declare that they have no competing interests.

Received: 23 February 2021 Accepted: 25 May 2021

Published online: 14 June 2021

\section{References}

1. Jung K, Hu H, Eyerly B, Lu Z, Chepngeno J, Saif $\sqcup$ (2015) Pathogenicity of 2 porcine deltacoronavirus strains in gnotobiotic pigs. Emerg Infect Dis 21:650-654. https://doi.org/10.3201/eid2104.141859

2. Wang $L$, Byrum B, Zhang $Y$ (2014) Detection and genetic characterization of deltacoronavirus in pigs, Ohio, USA, 2014. Emerg Infect Dis 20:12271230. https://doi.org/10.3201/eid2007.140296 
3. Jang G, Lee KK, Kim SH, Lee C (2017) Prevalence, complete genome sequencing and phylogenetic analysis of porcine deltacoronavirus in South Korea, 2014-2016. Transbound Emerg Dis 64:1364-1370. https:// doi.org/10.1111/tbed.12690

4. Madapong A, Saeng-Chuto K, Lorsirigool A, Temeeyasen G, Srijangwad A, Tripipat T, Wegner M, Nilubol D (2016) Complete genome sequence of porcine deltacoronavirus isolated in Thailand in 2015. Genome Announc 4:e00408-e416. https://doi.org/10.1128/genomeA.00408-16

5. Suzuki T, Shibahara T, Imai N, Yamamoto T, Ohashi S (2018) Genetic characterization and pathogenicity of Japanese porcine deltacoronavirus. Infect Genet Evol 61:176-182. https://doi.org/10.1016/j.meegid.2018.03. 030

6. Dong N, Fang L, Yang H, Liu H, Du T, Fang P, Wang D, Chen H, Xiao S (2016) Isolation, genomic characterization, and pathogenicity of a Chinese porcine deltacoronavirus strain CHN-HN-2014. Vet Microbiol 196:98-106. https://doi.org/10.1016/10.1016/j.vetmic.2016.10.022

7. Jung K, Hu H, Saif $\sqcup J$ (2017) Calves are susceptible to infection with the newly emerged porcine deltacoronavirus, but not with the swine enteric alphacoronavirus, porcine epidemic diarrhea virus. Arch Virol 162:23572362. https://doi.org/10.1007/s00705-017-3351-z

8. Boley PA, Alhamo MA, Lossie G, Yadav KK, Vasquez-Lee M, Saif LJ, Kenney SP (2020) Porcine deltacoronavirus infection and transmission in poultry, United States. Emerg Infect Dis 26:255-265. https://doi.org/10.3201/eid26 02.190346

9. Duan C, Ge X, Wang J, Wei Z, Feng WH, Wang J (2021) Ergosterol peroxide exhibits antiviral and immunomodulatory abilities against porcine deltacoronavirus (PDCoV) via suppression of NF-KB and p38/MAPK signaling pathways in vitro. Int Immunopharmacol 93:107317. https://doi.org/10. 1016/j.intimp.2020.107317

10. Ashida H, Mimuro H, Ogawa M, Kobayashi T, Sanada T, Kim M, Sasakawa C (2011) Cell death and infection: a double-edged sword for host and pathogen survival. J Cell Biol 195:931-942. https://doi.org/10.1083/jcb. 201108081

11. Chen WY, Wang M, Zhang J, Barve SS, McClain CJ, Joshi-Barve S (2017) Acrolein disrupts tight junction proteins and causes endoplasmic reticulum stress-mediated epithelial cell death leading to intestinal barrier dysfunction and permeability. Am J Pathol 187:2686-2697. https://doi. org/10.1016/j.ajpath.2017.08.015

12. Swain SL, McKinstry KK, Strutt TM (2012) Expanding roles for CD4 ${ }^{+}$T cells in immunity to viruses. Nat Rev Immunol 20:136-148. https://doi.org/10. 1038/nri3152

13. Levine AG, Mendoza A, Hemmers S, Moltedo B, Niec RE, Schizas M, Hoyos BE, Putintseva EV, Chaudhry A, Dikiy S, Fujisawa S, Chudakov DM, Treuting PM, Rudensky AY (2017) Stability and function of regulatory T cells expressing the transcription factor T-bet. Nature 546:421-425. https://doi. org/10.1038/nature22360

14. Hayden MS, Ghosh S (2008) Shared principles in NF-kB signaling. Cell 132:344-362. https://doi.org/10.1016/j.cell.2008.01.020

15. Wan S, Yi Q, Fan S, Fan S, Lv J, Zhang X, Guo L, Lang C, Xiao Q, Xiao K, Yi Z, Qiang M, Xiang J, Zhang B, Chen Y, Gao C (2020) Relationships among lymphocyte subsets, cytokines, and the pulmonary inflammation index in coronavirus (COVID-19) infected patients. Brit J Haematol 189:428-437. https://doi.org/10.1111/bjh.16659

16. Cao L, Ge X, Gao Y, Ren Y, Ren X, Li G (2015) Porcine epidemic diarrhea virus infection induces NF-KB activation through the TLR2, TLR3 and TLR9 pathways in porcine intestinal epithelial cells. J Gen Virol 96:1757-1767. https://doi.org/10.1099/vir.0.000133

17. Wei L, Zhu Z, Wang J, Liu J (2009) JNK and p38 mitogen-activated protein kinase pathways contribute to porcine circovirus type 2 infection. J Virol 83:6039-6047. https://doi.org/10.1128/JVI.00135-09

18. Yu D, Zhu H, Liu Y, Cao J, Zhang X (2009) Regulation of proinflammatory cytokine expression in primary mouse astrocytes by coronavirus infection. J Virol 83:12204-12214. https://doi.org/10.1128/JVI.00135-09

19. Whitmarsh AJ, Davis RJ (2000) A central control for cell growth. Nature 403:255-256. https://doi.org/10.1038/35002220

20. Duan C, Liu Y, Hao Z, Wang J (2021) Ergosterol peroxide suppresses porcine deltacoronavirus (PDCoV)-induced autophagy to inhibit virus replication via p38 signaling pathway. Vet Microbiol 257:109068. https:// doi.org/10.1016/j.vetmic.2021.109068

21. Chen Q, Gauger P, Stafne M, Thomas J, Arruda P, Burrough E, Madson D, Brodie J, Magstadt D, Derscheid R, Welch M, Zhang J (2015) Pathogenicity and pathogenesis of a United States porcine deltacoronavirus cell culture isolate in 5-day-old neonatal piglets. Virology 482:51-59. https://doi.org/ 10.1016/j.virol.2015.03.024

22. Yu J, Zhu Y, Yang G, Zhang W, Zhou D, Su J, Wang J (2017) Anti-inflammatory capacity of Lactobacillus rhamnosus GG in monophasic variant Salmonella infected piglets is correlated with impeding NLRP6 mediated host inflammatory responses. Vet Microbiol 210:91-100. https://doi.org/ 10.1016/j.vetmic.2017.08.008

23. Zhai X, Wang S, Zhu M, He W, Pan Z, Su S (2019) Antiviral effect of lithium chloride and diammonium glycyrrhizinate on porcine deltacoronavirus in vitro. Pathogens 8:144. https://doi.org/10.3390/pathogens8030144

24. Zhang Y, Xia L, Yuan Y, Li Q, Han L, Yang G, Hu H (2020) Rhodanine derivative LJ001 inhibits TGEV and PDCoV replication in vitro. Virus Res 289:198167. https://doi.org/10.1016/j.virusres.2020.198167

25. Brown AJ, Won JJ, Graham RL, Dinnon KH, Sims AC, Feng JY, Cihlar T, Denison MR, Baric RS, Sheahan TP (2019) Broad spectrum antiviral remdesivir inhibits human endemic and zoonotic deltacoronaviruses with a highly divergent RNA dependent RNA polymerase. Antiviral Res 169:104541. https://doi.org/10.1016/j.antiviral.2019.104541

26. Vancamelbeke $M$, Vermeire $S$ (2017) The intestinal barrier: a fundamental role in health and disease. Expert Rev Gastroenterol Hepatol 11:821-834. https://doi.org/10.1080/17474124.2017.1343143

27. Scaldaferri F, Pizzoferrato M, Gerardi V, Lopetuso L, Gasbarrini A (2012) The gut barrier: new acquisitions and therapeutic approaches. J Clin Gastroenterol 46:12-17. https://doi.org/10.1097/MCG.0b013e31826ae849

28. König J, Wells J, Cani PD, García-Ródena CL, MacDonald T, Mercenier A, Whyte J, Troost F, Brummer RJ (2016) Human intestinal barrier function in health and disease. Clin Transl Gastroenterol 7:e196. https://doi.org/10. 1038/ctg.2016.54

29. Kim Y, Lee C (2014) Porcine epidemic diarrhea virus induces caspaseindependent apoptosis through activation of mitochondrial apoptosisinducing factor. Virology 460-461:180-193. https://doi.org/10.1016/j.virol. 2014.04.040

30. Jung K, Hu H, Saif LJ (2016) Porcine deltacoronavirus induces apoptosis in swine testicular and LLC porcine kidney cell lines in vitro but not in infected intestinal enterocytes in vivo. Vet Microbiol 182:57-63. https:// doi.org/10.1016/j.vetmic.2015.10.022

31. Chung CY, Alden SL, Funderburg NT, Fu P, Levine AD (2015) Progressive proximal-to-distal reduction in expression of the tight junction complex in colonic epithelium of virally-suppressed $\mathrm{HIV}^{+}$individuals. PLOS Pathog 10:e1004198. https://doi.org/10.1371/journal.ppat.1004198

32. Krishna VD, Kim Y, Yang M, Vannucci F, Molitor T, Torremorell M, Cheeran MC (2020) Immune responses to porcine epidemic diarrhea virus (PEDV) in swine and protection against subsequent infection. PLoS One 15:e0231723. https://doi.org/10.1371/journal.pone.0231723

33. Channappanavar R, Perlman S (2017) Pathogenic human coronavirus infections: causes and consequences of cytokine storm and immunopathology. Semin Immunopathol 39:529-539. https://doi.org/10.1007/ s00281-017-0629-x

34. Mayor S (2020) Intensive immunosuppression reduces deaths in covid-19-associated cytokine storm syndrome, study finds. Brit Med J 370:m2935. https://doi.org/10.1136/bmj.m2935

35. Lee C, Kim Y, Jeon JH (2016) JNK and p38 mitogen-activated protein kinase pathways contribute to porcine epidemic diarrhea virus infection. Virus Res 222:1-12. https://doi.org/10.1016/j.virusres.2016.05.018

\section{Publisher's Note}

Springer Nature remains neutral with regard to jurisdictional claims in published maps and institutional affiliations. 